\title{
Analgesic Effects of Vibration and Transcutaneous Electrical Nerve Stimulation Applied Separately and Simultaneously to Patients with Chronic Pain
}

\author{
Régis Guieu, Marie-Françoise Tardy-Gervet and Jean-Pierre Roll
}

\begin{abstract}
The analgesic effects of transcutaneous electrical nerve stimulation (TENS) and vibratory stimulation (VS), used both separately and simultaneously, were compared in 24 patients suffering from chronic pain. We tested the hypothesis that these combined procedures might improve the pain reducing effects obtained with a single type of stimulation, since they make it possible to recruit a larger number of large diameter afferents and/or to increase the discharge frequencies. Four 35-minute treatment sessions (VS, TENS, VS+TENS, Sham stimulation) were run with each patient. The vibrations $(100 \mathrm{~Hz})$ and TENS $(100 \mathrm{~Hz})$ were applied to the surface of the painful region. The sham stimulation treatment consisted of positioning the TENS electrodes without actually delivering any current. The short form of the McGill pain questionnaire was used to assess the subjects' pain levels. The assessments took place immediately after any treatment $(0 \mathrm{~h}$.$) , and again 4$ hours and 24 hours later. The results showed that dual stimulation not only alleviated pain in more cases than either VS or TENS alone, but also had stronger and more long-lasting analgesic effects. On the other hand, all three types of stimulation used produced stronger analgesic effects than those obtained with the sham stimulation.
\end{abstract}

\begin{abstract}
RÉSUMÉ: Dans le travail présenté nous comparons sur 24 patients souffrant de douleurs chroniques, les effets analgésiques de stimulations nerveuses électriques trancutanées (SENT) et de stimulations vibratoires (SV) employées séparément et simultanément. Ces techniques analgésiques visent toutes les deux à accroître notablement le volume d'activité des afférences de gros diamètre de manière à bloquer les messages douloureux véhiculés par les fibres fines. L'hypothèse testée est que l'application simultanée, en recrutant un nombre plus important d'afférences de gros diamètre et/oú en augmentant les fréquences de décharge, doit permettre d'obtenir un effet antalgique accru? Quatre séances de traitement de 35 minutes ont été effectuées (SV, SENT, SV+SENT, Stimulation simulée). Les vibrations $(100 \mathrm{~Hz})$ et la SENT $(100 \mathrm{~Hz})$ ont été appliquées sur la surface douloureuse. Pour la stimulation simulée nous avons mis en place les électrodes de la SENT mais sans qu'aucun courant ne soit délivré. Pour mesurer la douleur nous avons utilsé la forme simplifée du questionnaire d'algie de McGill. L'évolution de la douleur a été appréciée immédiatement après l'application de l'un ou l'autre des différents traitements (0h.), 4 heures après et 24 heures après. Les résultats montrent que la double stimulation non seulement améliore plus de malades que la SV seule ou que la SENT seule, mais qu'elle permet également une amélioration plus importante et plus durable. Par ailleurs les effets analgésiques obtenus dans les trois conditions de stimulation sont très différents de ceux obtenus avec la stimulation simulée.
\end{abstract}

Can. J. Neurol. Sci. 1991; 18: 113-119

The "Gate control" theory put forward by Melzack and Wall in $1965^{1}$ has led to the development of various electrostimulation methods for relieving pain. The most widely used of these methods is undoubtedly Transcutaneous Electrical Nerve Stimulation (TENS), which consists of stimulating the afferent fibres in the painful area by means of electrodes placed on the skin, so as to set up an inhibitory control on the pain pathways. 2,3,4,5 The conventional method involves the use of high frequency, low intensity stimulations, which mainly recruits afferent fibres belonging to the $A \alpha \beta$ group.

Vibratory stimulation (VS), which has been known for a long time to have analgesic effects and is commonly used by physio-

From Laboratoire de Neurobiologie Humaine, Université de Provence, Marseille, France

Received July 24, 1990. Accepted October 23, 1990

Reprint requests to: M.F. Tardy-Gervet, Laboratoire de Neurobiologie Humaine - Université de Provence - URA CNRS 372 - Avenue Escadrille Normandie Niemen - 13397 Marseille Cedex 13 - France 
therapists, has only recently been investigated in patients suffering from acute $6,7,8,9,10$ and chronic pain. ${ }^{11,12,13,14}$ The effects of vibration on experimentally-induced pain have also be tested. ${ }^{15-21}$ The results of all the above studies combine to show that vibration can be a highly efficient means of alleviating pain, probably involving the activation of the large diameter afferent $A \alpha \beta$ fibres. The conditions under which vibration has usually been applied in these studies (probe applied to the skin; amplitudes ranging between 0.5 and $3 \mathrm{~mm}$; frequencies ranging between 10 and $200 \mathrm{~Hz}$ ) give rise to perceptual vibratory sensations, which suggest that cutaneous mechano-receptors are the main receptor type involved.

Microneurographic data obtained with human subjects have provided further information about the receptors involved. Numerous studies have shown that various receptors, both superficial and deep-lying, and of both the slowly and fast adapting types, are highly sensitive to vibration. 22.27 These receptors are mainly associated with $A \alpha \beta$ fibres 28 and respond to vibration over a wide range of frequencies ( 1 to $200-400 \mathrm{~Hz}$ ), even when the amplitudes are very low (less than $100 \mu \mathrm{m}$ ).

Muscle receptors are also activated by vibration, although to a lesser extent. Microneurographic studies in man have shown that the primary muscle spindle endings (Ia) are highly vibration-sensitive, generally at frequencies of up to $100-150 \mathrm{~Hz}{ }^{29-33}$ The conditions under which vibration has usually been applied in clinical studies designed to obtain analgesic effects have nevertheless not been the most appropriate for ensuring spindle activation. The most effective means of activating muscle spindles is known to consist of placing the vibrator perpendicular to a tendon. This type of stimulation is known in addition to give rise to illusory sensations of movement, as well as to motor responses in either the vibrated muscle or the antagonist muscle. ${ }^{31,34-36}$

The fact that both TENS and VS mainly activate the largediameter cutaneous afferents led us to compare the analgesic effects of these two techniques, used both separately and together on patients suffering from chronic pain. Our working hypothesis was that the analgesic effects obtained were more likely to be enhanced by the simultaneous procedure, with which a larger number of large-diameter fibres might be recruited than with either technique separately. Preliminary accounts of some of these results have been published. 37,38

\section{METhOdS}

\section{Patients}

Twenty-four patients suffering chronic pain, who had been admitted to the neuro-rheumatology ward, were used in the present study. They all gave their informed consent to the procedure, as required by the Helsinski convention. The patients were informed that they would undergo 4 sessions involving either electric or vibration treatment. No mention was made of the possibility that a placebo session might be included. The patients were 9 women and 15 men aged 19 to 79 , who had been in pain for more than three months (17 of the patients had been in pain for more than 6 months). The pathologies involved were as follows: 13 cases of low back pain (11 with sciatica; 1 with lumbar spondylosis; I with post-operative pain), 2 of tendinitis, 2 of scapular bursitis, 3 of bone pain ( 1 with vertebral osteoporosis; 1 with post traumatic dorsal rachialgia; 1 with post- radiotherapy rachialgia) and 4 of peripheral neuralgia (2 with cervical brachialgia; I with polyradicultitis; 1 with Pancoast Tobias syndrome).

All 24 patients had been receiving medical treatment up to that point with only slight if any success. The treatments included: various types of physiotherapy (infrared rays, massage, laser treatment, thalasso-therapy), and analgesic and anti-inflammatory drugs. No additional analgesic medication was administered during the study, except such medication as had been used prior to admission to hospital.

\section{Treatment procedures}

Vibratory stimulation (VS) Here we used a prototype consisting of a DC motor equipped with an eccentric mass set in a plastic casing, the base of which was adjustable in size and covered with a fine layer of rubber which served as an applicator. The power supply to the motor was variable and the vibration frequency could be selected as required; a frequency of $100 \mathrm{~Hz}$ was chosen. The vibrations were applied to an area of $4 \times 8 \mathrm{~cm}$ in the case of very localized pain (tendinitis, scapular bursitis, cervical brachialgia), and $8 \times 12 \mathrm{~cm}$ in the case of more widespread pain. Moderate pressure was exerted (between 8 and $30 \mathrm{~g} / \mathrm{cm} 2$, depending on the size of the applicator), and the amplitude was $1 \mathrm{~mm}$ peak to peak. The vibrations were applied directly to the painful area; in the case of lumbosciatica the vibrations were applied at lumbar level above the area where the sciatic roots emerge.

Transcutaneous electrical nerve stimulation (TENS) A Physiquelec stimulator (type: physiostim BF $+C$ ) was used. We adopted the conventional stimulation method involving biphasic shocks. The pulse width was 300 microseconds, the interval between positive and negative phases one millisecond, and the frequency $100 \mathrm{~Hz}$. The intensity was adjusted to a level producing paresthesia in the painful region. The electrodes consisted of silver plates measuring $8 \times 4 \mathrm{~cm}$ or $3 \times 4 \mathrm{~cm}$. The size of the plates chosen depended on the size of the painful area and the part of the body. For example, electrodes measuring $8 \times 4 \mathrm{~cm}$ were generally used on the lower limbs and the trunk and $3 \times 4$ $\mathrm{cm}$ plates on the upper limbs and neck. They were applied to the skin above the painful region when the pain was localized, and along the pathway of the pain in cases of radiating pain. In patients with sciatica, two electrodes were placed on each side at the emergence of the sciatic root and two electrodes on the lower limb (one electrode on the posterior aspect of the thigh and one in the popliteal fossa).

Combined stimulation (TENS + VS) The stimulation parameters used here were the same as those used with each technique separately, as described above. The TENS electrodes were placed on either side of the painful region, and the vibratory stimulation was applied between the electrodes.

Sham stimulation As a control, a sham stimulation session was performed in which the electrical stimulation electrodes were positioned without any current being delivered. Here we explained to the patients that they would be unable to feel anything during the session because the current intensity was very low. 


\section{Pain measurement}

The French version of the short form McGill pain questionnaire was used. ${ }^{39}$ This contains two intensity scales on which patients can rate the intensity of their present pain, and a qualitative scale on which 15 descriptors (11 sensory; 4 affective) are also given an intensity rating. The first intensity scale involves verbal descriptions. The patients were asked to rank their pain on a six point scale (no pain, mild pain, discomforting pain, distressing pain, horrible pain, excruciating pain). The second intensity scale is a visual analogue scale consisting of a tencentimetre line, on which patients were asked to indicate their pain intensity levels. The two extremities of this line correspond to "no pain" and "worst possible pain". Lastly, the patients were asked to choose the descriptors which described their pain most accurately. They were then asked to allot an intensity value ranging from 1 to 4 to each of the descriptors (none, mild, moderate, severe) among the following 15 descriptors (throbbing, shooting, stabbing, sharp, cramping, gnawing, hot-burning, aching, heavy, tender, splitting, tiring-exhausting, sickening, fearful, punishing-cruel).

Various values were obtained from the pain questionnaire: (l) the scores obtained on the Present Pain Intensity (PPI), where the patients' answers were rated between 1 and $6 ;(2)$ the score obtained on the visual analogue scale (VAS) in terms of $\mathrm{mm}$ along the scale; and (3) the average ratings of the descriptors chosen by the patients (pain rating index mean rank: PRI (MR); note that this is again an index of pain intensity).

The patients underwent the whole pain rating procedure before and after the treatment, and any changes in pain level were expressed as a percentage of the scores obtained prior to treatment (negative percentages were adopted by convention to express alleviation, and positive percentages to express aggravation of the pain). Each of these ratings was calculated for each patient, at each of the four sessions. The patients' pain levels were thus assessed before treatment, immediately after treatment, and again 4 hours and 24 hours later, which made it possible to describe the overall effects.

\section{Experimental procedure}

In order to statistically compare the effects of the four types of treatment, the patients were divided into 4 experimental groups, each of which received the 4 treatments in a different order (Table 1). Four 35-minute treatment sessions were run with each patient, at a rate of two a week (minimum interval between the treatment sessions $=48$ hours; most frequent inter$\mathrm{val}=72$ hours). At the first session, each patient was asked to specify the characteristics of his/her pain, the circumstances under which the symptoms first occurred, and what treatment was being applied. The 3 pain rating procedures were then presented before and immediately after the treatment, and again 4 and 24 hours later.

\section{Descriptive analysis}

\section{Results}

The initial pain intensity ratings obtained on the visual analogue scale (VAS) at the first session ranged from $30 \%$ to $100 \%$, depending on the patients (Figure 1). The four experimental groups were roughly similar, since the mean initial pain was $65 \%$ in group $\mathrm{A}, 62 \%$ in group $\mathrm{B}, 68.2 \%$ in group $\mathrm{C}$ and $77.3 \%$ in group D.
The pain alleviation obtained after the four treatment sessions is shown in Figure 2. This was assessed by subtracting the pain rating recorded 24 hours after the last treatment session

Table 1: Experimental procedure. The numbers correspond to the order of the treatment sessions.

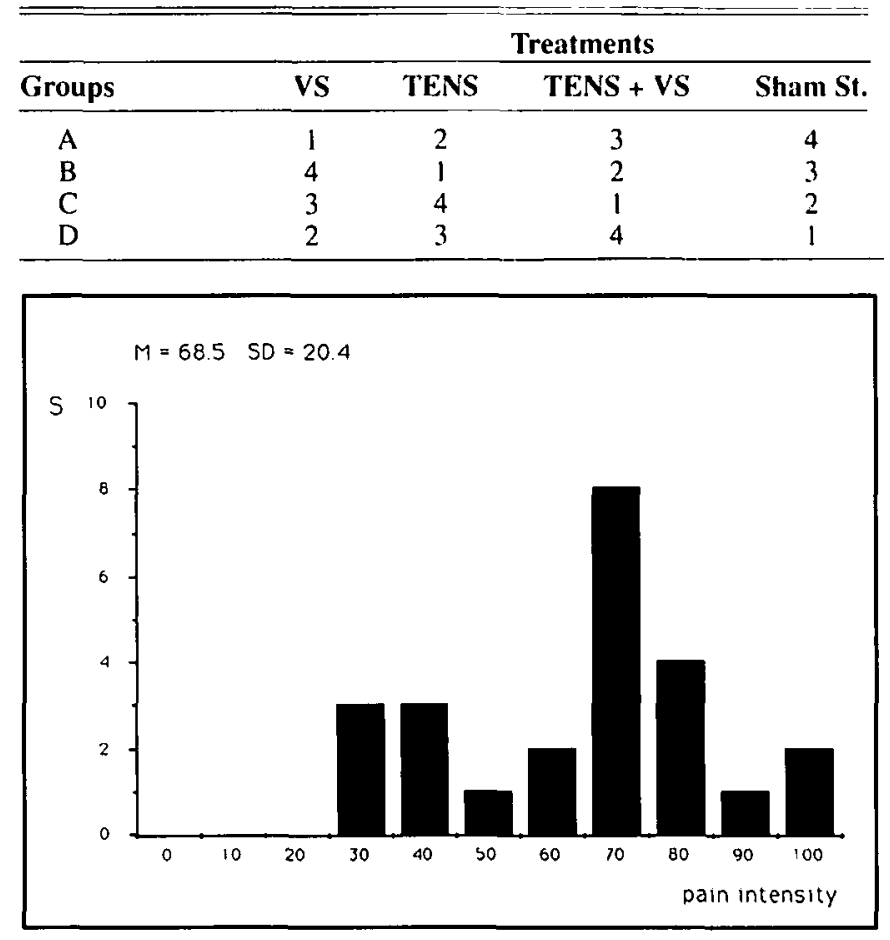

Figure I - Histogram showing the pain distribution among 24 patients prior to treatment. as assessed on the visual analog scale (VAS). On the ordinate: number of subjects (S). On the abscissa: pain intensity divided into 10 classes ranging from 0 (no pain) to 100 (worst possible pain). $M$ : mean, $S D$ : standard deviation.

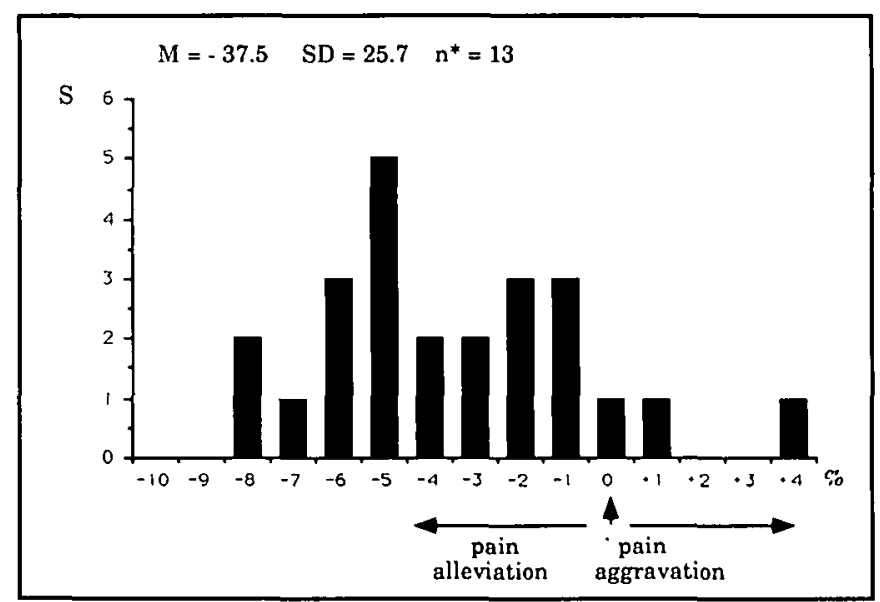

Figure 2 - Histogram showing the distribution of the analgesic effects observed after the 4 treatment sessions, as assessed on the VAS. Here the pain intensity rating levels recorded 24 hours after the last treatment were subtracted from the initial pain levels. On the ordinate: number of subjects $(S)$; on the abscissa: percentage alleviation (negative figures) and aggravation (positive figures). The interval between classes was 10 and the individual values ranged from $100 \%$ to $+50 \%$ (note that only the upper values obtained with each class are indicated on the abscissa). M: mean: SD: standard deviation; $n^{*}$ : number of patients with pain reduction of more than $30 \%$. 
from the initial pain rating. The values used to assess any changes in the pain levels were always those based on the VAS. It can be seen from the histogram and the accompanying data (in particular, the means and the number of patients in whom the pain levels were reduced by more than $30 \%$ ) that in 21 patients, the four sessions helped to reduce the pain levels. This alleviation amounted to more than $30 \%$ in 13 of them.

The analgesic effects of various types of treatment with time are compared in Figure 3. It can be seen from the histograms that whatever the time interval after treatment $(0 \mathrm{~h}, 4 \mathrm{~h}, 24 \mathrm{~h})$, the combine stimulations (TENS + VS) had greater analgesic effects than those obtained by applying VS or TENS alone. This can be seen not only from the mean values, but also from the number of patients who showed improvement, particularly those in which pain relief of more than $30 \%$ was achieved. It is worth noting that combined stimulation brought about pain relief in all the patients $0 \mathrm{~h}$ after treatment, which persisted in 23 out of the 24 patients $4 \mathrm{~h}$ after treatment. Combined stimulation therefore relieved pain both more efficiently and in a larger number of patients than the single procedures; it can also be said to have had more durable analgesic effects, since these were greater $24 \mathrm{~h}$ after treatment than the effects of the single procedures. It should be noted in addition that VS was slightly more effective than TENS on the average, and in terms of the number of patients

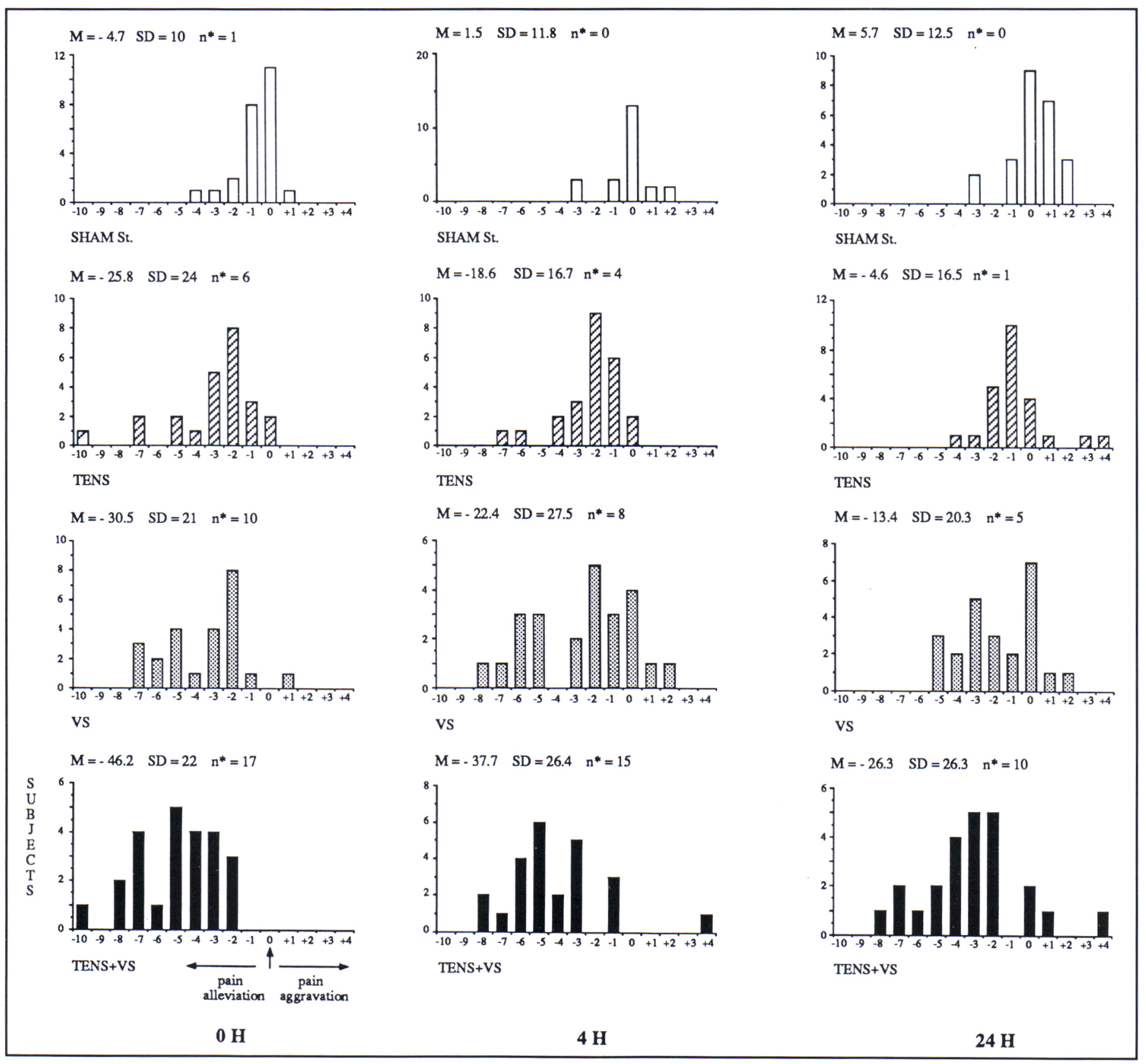

Figure 3 - Changes in pain intensity with time after application of three types of analgesic stimulation, based on the VAS. Pain levels, expressed as percentages of the scores obtained before stimulation, are given in the form of histograms corresponding to the four types of treatment session (TENS plus VS; VS alone; TENS alone; Sham stimulation) and the three time-intervals after the treatment (immediately after; 4 hours after and 24 hours after). Same conventions as in Figure 2. 
with pain reductions of more than $30 \%$. In addition, all three types of analgesic stimulation were consistently much more effective than the sham stimulation, both on the average and in terms of the number of patients in whom pain was relieved. The last point worth mentioning is that from the patients' point of view, although both TENS and VS were said by the patients to be pleasant, VS was generally preferred.

\section{Quantitative analysis}

The VAS data collected on the patients' pain levels at various times were subjected to a $4 \times 4 \times 3$ analysis of variance (groups $\times$ types of treatment $x$ number of hours after treatment). The pain levels were not found to vary significantly from one group of patients to another (F $3.30=1.5, p>0.5)$. The only significant factors at work were found to be the type of treatment $(\mathrm{F} 3.60=$ $23.4 \mathrm{p}<.001)$ and the time elapsing after the treatment $(\mathrm{F} 2.40$ $=51.8, \mathrm{p}<.001$ ). Looking more closely at the specific factors, it can be seen from Table 2 that combined stimulation (TENS + VS) was significantly more effective than VS or TENS alone, at all the times considered $(0 \mathrm{~h}, 4 \mathrm{~h}$ and $24 \mathrm{~h})$. On the other hand, the efficiency of VS did not differ significantly from that of TENS at any of these three times. All three treatments consistently showed highly significant differences, however, from the sham stimulation.

It was decided to examine in greater detail the pain rating scores obtained on the visual analogue scale (VAS). This scale is the most exact, since it is a continuous scale, whereas the other two scales used involved a series of steps (5 steps in the case of PPI and 3 steps in the case of PRI(MR)). In order to relate these scales to each other, however, we first calculated a Spearman rank correlation coefficient (Rs) on all the data. The results show that the three scales were correlated to a highly significant degree (VAS/PPI): $\mathrm{Rs}=0.81, \mathrm{p}<.001$; VAS/PRI: $\mathrm{Rs}=0.72$, $\mathrm{p}<.001 ;$ PPI/PRI: Rs $=0.7, \mathrm{p}<.001)$.

\section{Discussion}

The present study on 24 patients shows that both TENS and VS applied separately are effective means of reducing pain. In all the cases studied, the results obtained with each of these methods were a great improvement on the sham stimulation not only immediately after application of the stimulation, but also some time later. These methods were more successful with some patients than with others; however, and in some cases they were ineffective. These findings are in agreement with previously published results. $2,4,5,11-14$ If one looks at the results of all the treatment sessions combined (Figure 2), it can be seen that the total analgesic effects achieved were greater than those resulting from the dual stimulation session alone (see histogram in Figure 3 showing the effects of TENS + VS after $24 \mathrm{~h}$ ). This indicates that the analgesic effects of these techniques can be enhanced by multiplying the number of sessions.

The most noteworthy finding to emerge from this study, however, is the fact that dual stimulation (TENS + VS) was found to be significantly more effective than either VS or TENS applied separately. Not only was pain alleviated in a larger number of patients, but the analgesic effects obtained were stronger and longer lasting. The persistence of these analgesic effects is worth noting as one of the main advantages of the combined stimulation technique, which could be widely used in clinical practice. When used, for example, to treat a patient with painful legs and moving toes, complete pain relief was obtained which lasted for more than 24 hours. Four months after the patient started self treatment at home, 3-4 sessions of combined stimulation per week sufficed to relieve his pain completely. ${ }^{40}$

How are we to account for the enhanced analgesic effects observed as the result of combined stimulation? The explanation may be that both types of stimulation do not recruit exactly the same population of large-sized afferent fibres. The first argument in favour of this hypothesis is based on perceptual data. The two kinds of analgesic stimulation do not in fact give rise to identical sensations. If either type is discontinued during dual application, subjects are able to clearly and accurately discriminate between the two types. The second argument has to do with the nature of the stimulus. Vibratory stimulation diffuses more widely, and although attenuating effects naturally occur, it penetrates quite deeply to areas which can be quite distal from the site of application. This diffusion capacity obviously depends largely on the transmission properties of the underlying tissues, and is unquestionably enhanced by the proximity of bone tissue. More specifically, VS probably activates the vibration-sensitive mechano-receptors which are located in the deep skin layers, the connective tissue, and the periosteum (especially the Pacinian corpuscules). TENS, when applied in the conventional manner, probably recruits a somewhat different fibre population, since the intensity of the current decreases very sharply as it penetrates the skin layers. Lastly, the afferent information will probably

Table 2: Comparison between the analgesic effects obtained with the 4 types of treatment (TENS + VS, VS, TENS, Sham stimulation) after 3 different time-intervals had elapsed (immediately after, 4 hours after and 24 hours after the treatment). Results of an analysis of variance (specific factors) conducted on the data collected using the visual analog scale (VAS).

\begin{tabular}{|c|c|c|c|c|c|c|c|c|c|}
\hline & & & VS & & & TENS & & & Sham Stimulation \\
\hline VS & & & & $\begin{array}{r}0 \mathrm{~h} \\
4 \mathrm{~h} \\
24 \mathrm{~h}\end{array}$ & $\begin{array}{l}\text { N S } \\
\text { NS } \\
\text { N S }\end{array}$ & & $\begin{array}{r}0 \mathrm{~h} \\
4 \mathrm{~h} \\
24 \mathrm{~h}\end{array}$ & $\begin{array}{l}\mathbf{S} \\
\mathbf{S} \\
\mathbf{S}\end{array}$ & $\begin{array}{l}(F=30.32, p<.001) \\
(F=13.5, p<.001) \\
(F=21.09, p<.001)\end{array}$ \\
\hline
\end{tabular}

N.B.: In all these comparisons, $F$ is given for $(2.20)$ degrees of freedom. 
be differently organized depending on whether the receptors are activated directly by a mechanical stimulus or by an electrical stimulus, which is likely to synchronously activate all the afferent fibres.

The efficacy of combined stimulation might then be attributable to the fact that it leads to the recruitment of afferent populations with different types of sub-modalities and different numbers. The discharge frequencies of these afferents might also be increased by combined stimulation. These are only tentative answers, however: to obtain more definite explanations it will be necessary to carry out micro-neurographic unitary recordings on the afferent fibres recruited by TENS + VS, TENS and VS.

As regards the question as to what pain control mechanisms are triggered by the activation of large diameter primary afferents, all that is known is that the pain control may result from the central blocking of nociceptive messages at the level of the dorsal horn, and/or from inhibitory controls of suprasegmental origin. ${ }^{1-5,41-43}$ The liberation of endogenous opioids has often been put forward to account for analgesic effects of this kind, but there seems to be no evidence supporting this idea either in the case of the conventional TENS method or in that of VS, since the analgesic effects of these two procedures are not reversed by naloxone. ${ }^{44-48}$ These conclusions should be treated with caution, however, because of the complexity of the effects of naloxone.49-52 Another set of arguments which is worth considering to explain the potentiation of analgesic effects observed when dual stimulation was applied have to do with the autonomic nervous system. TENS is known to bring about changes in sympathetic tone; this is why it causes local vasodilation, which is accompanied by a reddening of the skin and a rise in skin temperature.53.54 The same occurs with VS, since we, like Lundeberg 11.17 noted the occurrence of vasodilatation at the vibrator site. The mechanisms underlying this vasodilation have not yet been elucidated. 55.56 This synergetic action of the two types of stimulation on the sympathetic system might thus at least partly explain why the combined procedure is particularly effective. Lastly, vibration can lead to local myorelaxation because it acts like a massage and thus enhances the overall analgesic effects.

The above investigation calls for a few final methodological comments. We would like to stress the excellent degree of correlation found to exist among the three pain intensity rating scales used here; this confirms that the short-form McGill pain questionnaire is a highly useful and reliable means of measuring pain. This correlation also makes it possible to evaluate the care with which the patients have answered the questionnaire, which makes our results all the more valid.

In conclusion, the results of the above study confirm our initial working hypothesis, since they show that by combining VS with TENS, it is possible to improve the analgesic effects obtained with either procedure separately. This potentiation observed in patients with various pathologies requires further investigation to determine which types of pathology are most sensitive to the combined stimulation and whether the potentiation persists during long treatments.

\section{ACKNOWLEDGEMENTS}

The helpful comments by Dr. D. Bowsher and Dr. J.C. Willer on an earlier version of the manuscript are gratefully acknowledged. This work was supported by Ministère de la Recherche et de l'Industrie and by Fondation pour la Recherche grants. English translation by Dr. Jessica Blanc.

\section{REFERENCES}

1. Melzack R, Wall PD. Pain mechanism: a new theory. Science 1965; 150: 971-978.

2. Andersson SA. Pain control by sensory stimulation. In: Bonica JJ, Liebeskind JC, Albe-Fessard DG, eds. Advances in Pain Research and Therapy. New York: Raven Press 1979; 3: 569-585.

3. Boureau F, Willer JC. La douleur, exploration, traitement par neurostimulation et électroacupuncture. Paris: Masson, eds. $1979 ; 119 \mathrm{p}$.

4. Mannheimer JS, Lampe GN. Clinical transcutaneous electrical nerve stimulation. Philadelphia: Davis Company, ed. 1984; 636 p.

5. Meyerson BA. Electrostimulation procedures: effects, presumed rationale, and possible mechanisms. In: Bonica JJ, Liebeskind JC, Albe-Fessard DG, eds. Advances in Pain Research and Therapy. New York: Raven Press 1983; 5: 495-534.

6. Ekblom A, Hansson PT. Effects of conditioning vibratory stimulation on pain threshold of the human tooth. Acta Physiol Scand 1982; 114: 601-604.

7. Ekblom A, Hansson PT. Extra segmental transcutaneous electrical nerve stimulation and mechanical vibratory stimulation as compared to placebo for the relief of acute orofacial pain. Pain 1985; 23: 223-229.

8. Hansson P, Ekblom A. Afferent stimulation-induced pain relief in acute orofacial pain and its failure to induce sufficient pain reduction in dental and oral surgery. Pain 1984; 20: 273-278.

9. Lundeberg T, Nordemar R, Ottosson D. Pain alleviation by vibratory stimulation. Pain 1984; 20: 25-44.

10. Ottosson D, Ekblom A, Hansson P. Vibratory stimulation for the relief of pain of dental origin. Pain 1981; 10: 7-45.

11. Lundeberg T. Vibratory stimulation for the alleviation of chronic pain. Acta Physiol Scand 1983; 523: 1-51 (Suppl).

12. Lundeberg $T$. The pain-suppressive effect of vibratory stimulation and transcutaneous electrical nerve stimulation (TENS) as compared to aspirin. Brain Res 1984; 294: 201-209.

13. Lundeberg $T$. Long-term results of vibratory stimulation as a pain relieving measure for chronic pain. Pain 1984; 20: 13-23.

14. Lundeberg T, Ottoson D, Hakansson, et al. Vibratory stimulation for the control of intractable chronic orofacial pain. $\mathrm{ln}$ : Bonica $\mathrm{JJ}$, Lindblom V, Iggo A, eds. Advances in Pain Research and Therapy. New York: Raven Press 1983; 5: 555-561.

15. Bellini F, Duranti R, Galletti R, et al. Variations in muscular pain threshold and eyeblink response induced by vibratory stimulation. In: Bromm B, eds. Pain Measurement in Man. Neurophysiological Correlates of Pain. Amsterdam: Elsevier, 1984; 135-141.

16. Duranti R, Pantaleo T, Bellini F. Increase in muscular pain threshold following low frequency-high intensity peripheral conditioning stimulation in humans. Brain Res 1988; 452: 66-72.

17. Lundeberg T, Abrahamsson P, Bondesson L, et al. Effect of vibratory stimulation on experimental and clinical pain. Scand J Rehab Med 1988; 20: 149-159.

18. Pantaleo T, Duranti R, Bellini F. Effects of vibratory stimulation on muscular pain threshold and blink response in human subjects. Pain 1986; 24: 239-250.

19. Pertovaara A. Modification of human pain threshold by specific tactile receptors. Acta Physiol Scand 1979; 107: 339-341.

20. Sherer CL, Clelland JA, O'Sullivan P, et al. The effect of high frequency vibration on cutaneous pain threshold. Pain 1986;25: 133-138.

21. Wall PD, Cronly-Dillon SA. Pain, itch, and vibration. Arch Neurol 1960; 2: 365-375.

22. Johansson RS, Vallbo AB. Tactile sensory coding in the glabrous skin of the human hand. Trends Neurosci 1983; 6: 27-32.

23. Konietzny F, Hensel H. Response of rapidly and slowly adaptating mechanoreceptors and vibratory sensitivity in human hair skin. Pflügers Arch 1977; 368: 39-44. 
24. Lundstöm R. Responses of mechanoreceptive afferent units in the glabrous skin of the human hand to vibration. Scand J Work Environ Health 1986; 125: 413-416.

25. Lundstöm R, Johansson RS. Acute impairment of the sensitivity of the skin mechanoreceptive units caused by vibration exposure of the hand. Ergonomics 1986; 29: 687-698.

26. Ribot-Ciscar E, Vedel JP, Roll JP. Vibration sensitivity of slowly and rapidly adaptating cutaneous mechanoreceptors in the human foot and leg. Neurosci Lett 1989; 104: 130-135.

27. Vedel JP, Roll JP. Response to pressure and vibration of slowlyadaptating cutaneous mechanoreceptors in the human foot. Neurosci Lett 1982; 34: 289-294.

28. Willis WD, Coggeshall RE. Sensory mechanisms of the spinal cord. New York: Plenum Press, eds. 1978; 485 p.

29. Burke D, Hagbarth KE, Lofstedt L, et al. The response of human muscle spindle endings to vibration of non contracting muscles. J Physio 1976; 261: 673-693.

30. Burke D, Hagbarth KE, Lofstedt L, et al. The response of human muscle spindle endings to vibration during isometric contraction. J Physiol 1976; 261: 695-711.

31. Roll JP, Vedel JP. Kinaesthetic role of muscle afferents in man, studied by tendon vibration and microneurography. Exp Brain Res 1982; 47: 177-190.

32. Roll JP, Vedel JP, Ribot, E. Alteration of proprioceptive messages induced by tendon vibration in man: a micro-neurographic study. Exp Brain Res 1989; 76: 213-222.

33. Vedel JP, Roll JP. Muscle spindle contribution to the coding of motor activities in man. In: Massion J, Paillard J, Schultz W, et al., eds. Neural Coding of Motor Performance. Exp Brain Res 1983; 7: 253-265 (Suppl).

34. Eklund G. Position sense and state of contraction; the effects of vibration. J Neurol Neurosurg Psychiatry 1972; 35: 606-611.

35. Goodwin GM, McCloskey DI, Matthews PBC. The contribution of muscle afferents to kinesthaesia shown by vibration induced illusions of movement and by the effects of paralysing joint afferents. Brain 1972; 95: 705-748.

36. Roll JP, Gilhodes JC, Tardy-Gervet MF. Effets perceptifs et moteurs des vibrations musculaires chez l'homme normal: mise en évidence d'une réponse dans les muscles antagonistes. Arch Ital Biol 1980; 118: 51-71.

37. Guieu R, Tardy-Gervet MF, Roll JP. Effets antalgiques des vibratjons mécaniques associées à des stimulations électriques transcutanées. In: INRS eds. Proceedings of United Kingdom and French joint meeting on Human Response to Vibration. Vandoeuvre-les-Nancy: INRS Press 1988; 230-239.

38. Guieu R, Tardy-Gervet MF, Roll JP. Vibrations applied simultaneously with transcutaneous electrical nerve stimulation as means of treating chronic pain. Eur J Neurosci 1989; 2: 170 (Suppl).
39. Melzack R. The short-form McGill pain questionnaire. Pain 1987; 30: 191-197.

40. Guieu R, Tardy-Gervet MF, Blin O, et al. Pain relief achieved by transcutaneous electrical nerve stimulation and or vibratory stimulation in a case of painful legs and moving toes. Pain 1990; 42 43-48.

41. Besson JM, Chaouch A. Peripheral and spinal mechanisms of nociception. Physiol Rev 1987; 67: 67-186.

42. Besson JM, Guilbaud G, Abdelmounene M, et al. Physiologie de la nociception. Paris: J Physiol 1982; 78: 7-107.

43. Melzack R, Wall PD. Le défi de la douleur, $3^{\circ}$ édition (English translation of: "Challenge of pain"). Montmagny: Edisem 1989; 290 p.

44. Abram SE, Reynolds AC, Cusick JF. Failure to naloxone to reverse analgesia from transcutaneous electrical stimulation in patients with chronic pain. Anesth Analg 1981; 60:81-84.

45. Guieu R, Dano P, Tardy-Gervet MF, et al. Effets de la Naloxone sur l'antagie induite par les stimulations vibratoires. Press Méd 1989; 24: 1207.

46. Hansson P, Ekblom A. Influence of naloxone on relief of acute orofacial pain by transcutaneous electrical nerve stimulation or vibration. Pain 1986; 24: 323-329.

47. Lundeberg T. Nalaxone does not reverse the pain-reducing effect of vibratory stimulation. Acta Anesthesiol Scand 1985; 29: 212-216.

48. Sjölung BH, Eriksson MBE. The influence of naloxone on analgesia produced by peripheral conditioning stimulation. Brain Res 1979; 173: 295-301.

49. Cesselin F. Endorphines et nociception. Rev Neurol 1986; 142: 649-670.

50. Millan MJ. Multiple opioïd systems and pain. Pain 1986: 27: 303 347.

51. Gillman MA, Lichtigfeld FJ. A pharmacological overview of opioid mechanisms and mediating analgesia and hyperalgesia. Neurological Research 1985; 7: 105-1109.

52. Levine JD, Gordon NC, Fields HL. Naloxone dose dependently produces analgesia and hyperalgesia in postoperative pain. Nature 1979; 278: 740-741.

53. Abram SE, Asiddao CB, Reynolds AC. Increased skin temperature during transcutaneous electrical stimulation. Anesth Analg 1980; 59: $22-25$.

54. Kjartansson J, Lundeberg T, Korlof B. Transcutaneous electrical nerve stimulation (TENS) in ischemic tissue. Plast Reconstr Surg $1988 ; 81: 813-814$

55. Hyvärinen J, Pykkö J, Sunberg S. Vibration frequencies and amplitudes in the aetiology of traumatic vasospastic disease. Lancet $1973 ; 14: 791-793$.

56. Skoglund $C R$. Vasodilation in human skin induced by low amplitude high frequency vibration. Clin Physiol 1989; 9: 361-369. 